\title{
A Project to Improve the Process and Practices of Provision of Diet to Inward Patients in a Government Hospital, Sri Lanka
}

\author{
SMNS Maleesha Mallawarachchi ${ }^{1}, \mathrm{CH}$ Mallawarachchi ${ }^{2}, \mathrm{KCS}$ Dalpatadu ${ }^{3}$
}

\begin{abstract}
Aim: The research project was implemented in Base Hospital Warakapola (BHW) with the aim of improving provision of diet for inward patients in BHW.

Materials and methods: The process of providing diet to inward patients in BHW was mapped and gaps were assessed. A patients' survey, a checklist to assess consumption of hospital food, desk review of records, and key informant interviews (KIls) were used.

Results: The menus were not appealing, the patients were unaware of the menu till the food was served, and their preferences were never considered when ordering diet. Tea and soup were served too close to times of main meals. It was found that the diet requirements were estimated assuming the patient who has requested diet for a given day would need all three meals. But it was noted that only $11.64 \%$ (39/335) inward patients expected all three meals from the hospital. The food wastage, calculated by the number of diets not consumed, was $24.26 \%$ in the preintervention phase. Existing diet menus were modified by offering a diet with appealing variety in texture and color. The schedule of diet menu for each day was displayed in all wards. Estimation of diet requirement was improved by introducing a form to record diet requirements attached to the bed head ticket (BHT) of each patient to be filled by the nursing officer (NO) every morning. Post-interventional KIls and survey of patients showed that satisfaction of staff and patients regarding the process and practices had increased. Wastage of food had been reduced significantly to $9.47 \%$.

Conclusion: The process and practices of providing diet to hospitalized patients were assessed and it was found that there were gaps in patients' satisfaction on the menu, timeliness, and appearance of food and there was a significant waste of food. The project improved the issues identified. Keywords: Diet, Diet ordering form, Food wastage, Government hospital, Inward patients, Menu, Patients' satisfaction. International Journal of Research Foundation of Hospital and Healthcare Administration (2019): 10.5005/jp-journals-10035-1111
\end{abstract}

\section{INTRODUCTION}

Provision of diet to inward patients free of charge is a core component of total care in the Sri Lankan health system. A patient's diet for a day includes the entire requirement of food for 24 hours starting from 12 noon in each day to 12 midnight of the following day.

The objectives of provision of diet to inward patients are as follows:

- To provide a relevant diet depending on the illness

- To provide a hygienically cooked balanced meal

- To serve patients with their meals at a fixed time avoiding disturbances to other patient care activities in the ward

- To facilitate the poor patients have the relevant diet especially from distant areas

- To prevent unhygienic food being consumed by inward patients

- To restrict unauthorized visitors from coming to the wards under the pretext of bringing food to their patients

- To prevent pilferage

The raw provisions are ordered each day considering the number of diets required for patients in need of hospital food, by 11:00 am on each day (Ministry of Health, Sri Lanka, 1995). A clerk is assigned to receive the raw material from the supplier. Distribution of diets from the kitchen to the wards takes place in bulk, in the presence of diet stewardess. The nursing sister (NS) or nursing officer (NO) in charge should take over the food brought to the ward by minor staff and distribute to patients.

The diet clerk must visit each ward daily and scan each bed head ticket (BHT) manually to calculate the diet order. The process
${ }^{1}$ Department of Health, Ministry of Health, Colombo, Sri Lanka

${ }^{2}$ Department of Health, Medical Research Institute, Colombo, Sri Lanka ${ }^{3}$ Department of Health, Institute for Health Policy, Colombo, Sri Lanka Corresponding Author: SMNS Maleesha Mallawarachchi, Department of Health, Ministry of Health, Colombo, Sri Lanka, Phone: +94 772325410, e-mail: navodasandamali79@gmail.com

How to cite this article: Mallawarachchi SMNSM, Mallawarachchi $\mathrm{CH}$, Dalpatadu KCS. A Project to Improve the Process and Practices of Provision of Diet to Inward Patients in a Government Hospital, Sri Lanka. Int J Res Foundation Hosp Healthc Adm 2019;7(2):85-90.

Source of support: Nil

Conflict of interest: None

of estimating and recording the number of diets required each day is time-consuming and error-prone. It is not efficient or workerfriendly.

Base Hospital Warakapola (BHW) is one of the secondary care government hospital serving more than 500 patients daily while functioning as a referral center for number of smaller local hospitals in the district of Kurunegala. Catering to the hospitalized patients with an appropriate diet timely, minimizing food waste, and using limited human resources effectively have been challenging for the hospital management.

Basic amenities have been proven to be among the factors that affect patient satisfaction in hospitals. ${ }^{2}$ Yet hospital diet is reported to be one of the dissatisfiers of patients and relatives. ${ }^{3}$ Exploring the gaps that exist between patients' perceptions and expectations

() The Author(s). 2019 Open Access This article is distributed under the terms of the Creative Commons Attribution 4.0 International License (https://creativecommons. org/licenses/by-nc/4.0/), which permits unrestricted use, distribution, and non-commercial reproduction in any medium, provided you give appropriate credit to the original author(s) and the source, provide a link to the Creative Commons license, and indicate if changes were made. The Creative Commons Public Domain Dedication waiver (http://creativecommons.org/publicdomain/zero/1.0/) applies to the data made available in this article, unless otherwise stated. 
may improve the quality of diet services not only to maximize patient satisfaction but also to aid in speedy recovery from illness. ${ }^{4}$

Therefore, the issues in providing diet to patients need to be identified and evaluated to ease out the bottlenecks in order to improve the utility services of the hospital.

The provision of food to patients remains a multidimensional phenomenon, which is yet to be explored despite the wealth of studies performed all over the world.

Diet services of a hospital are of utmost importance as they affect the patient's satisfaction and the quality of the overall care for the patient. Optimal supply of food is identified as a prerequisite for optimization of specific treatment offered to patients. ${ }^{5}$ Although the food service in a hospital is a vital component of the process of patient care, studies have pointed out gaps in the quality of such services worldwide. ${ }^{6}$

Feeding is not just a significant element of comfort for patients during their hospital stay but also a vital necessity. ${ }^{7}$ Issues with practical aspects of the hospital's food provision are among the recognized factors for inadequate nutritional care offered to the patients. ${ }^{8}$ It is of utmost importance that public health care institutions preserve the food and nutrition rights of the human, which are considered among the most widely violated economic rights of people. ${ }^{9}$

Insufficient food intake during hospital stay, which remains a largely unrecognized issue in hospitals, worsens the degree of malnutrition and is associated with higher morbidity, increased length of stay, and mortality. ${ }^{10}$ The Australasian Nutrition Care Day Survey (ANCDS), which is the largest multicenter study in the region, focused on the prevalence of malnutrition and poor food intake in Australian and New Zealand hospitals and revealed that malnutrition and poor food intake were independently associated with in-hospital mortality.

The study further found that the median length of stay of patients who consumed less $(<25 \%)$ amount of food offered from hospital was significantly longer. ${ }^{11}$ The fact highlights the need to emphasize the attention on clinical nutrition in all health care settings.

Food wastage observed in hospitals has raised the need of reviewing hospital feeding policies. ${ }^{12}$ Researchers have observed that higher food wastage in health care facilities is associated with delays in serving food and poor presentation of diets. ${ }^{13}$

Huge total waste exceeding $40 \%$ of the hospital food served has been reported in studies. ${ }^{12}$ Nonconsumption of food creates extra costs while the wasted resources could be used to enhance other aspects of health care. ${ }^{14}$

Rigid administrative regulations leading to less flexible catering and feeding policies of hospitals minimize the opportunity for patients' choice in food selection. Allowance for menu choices for patients has been suggested to improve the compliance with the diet plans. $^{15}$

The interference with meals by ward rounds and procedures has been identified to negatively affect the food intake during hospitalization. ${ }^{16}$ Proper timing of serving the food and the availability of undisturbed location to consume them are identified to promote the food intake during the hospital stay. ${ }^{15}$

In the dynamic environment of health care, the hospital diet service practices need to be improved keeping up the pace with change. Novel concepts such as on-site catering, self-operated food kiosks, etc., are being discussed in hospital industry worldwide. ${ }^{17}$ Yet, selection of best measures to improve the process and practices in providing diet to hospitalized patients in the Sri Lankan health care setup must be well supported with a scientific evidence and a strategic approach.

\section{Materials and Methods}

The project was carried out from January 2019 to June 2019. The instruments used for the study included the following:

\section{A Patients' Survey}

The interviewer-administered questionnaire was used for the patient satisfaction survey regarding the diet provided and the process and practices of its provision.

The questionnaire was initially prepared in English after reviewing relevant literatures and the finalized questionnaire was then translated into Sinhala and Tamil and retranslated back into English to ensure the consistency. The questionnaire was pretested and validated.

A five-point Likert scale rating of very dissatisfied, dissatisfied, neutral, satisfied, and extremely satisfied was used to gather data on patients' satisfaction on following aspects:

- Timeliness in provision of food

- Cleanliness in food handling

- Hospitality of the staff when providing food

- General presentation/appearance of food

- Taste of food

- Aroma of food

- Freshness of food

To calculate the level of patient satisfaction on each aspect, very dissatisfied and dissatisfied were considered as dissatisfied and satisfied and very satisfied were considered as satisfied. Individuals with neutral rating responses were excluded.

Four hundred inward patients were recruited for the survey and interviewed. The number of patients selected for participation for the survey from each ward was calculated based on the proportion of admissions from each ward in the first quarter of year 2018 and the patients were selected within each ward by convenient sampling.

\section{Key Informant Interviews}

Key informant interviews (KIls) were held with:

- Medical superintendent, BHW

- NSs of BHW

- Diet clerk of BHW

- Diet stewardess of BHW

\section{Desk Review}

The desk review of secondary data relevant to quantify provision of diets to the patient was carried out, namely, by accessing:

- Records of diet clerk

- Records of kitchen

\section{Checklist}

The checklist was developed and used to estimate waste of food by assessing the number of diets ordered and number of diets refused by patients when it was served in each ward.

\section{Results}

The process of providing diet to inward patients in BHW was studied extensively and mapped (Flowchart 1). 
Flowchart 1: Process map of providing diet to inward patients in Base Hospital Warakapola

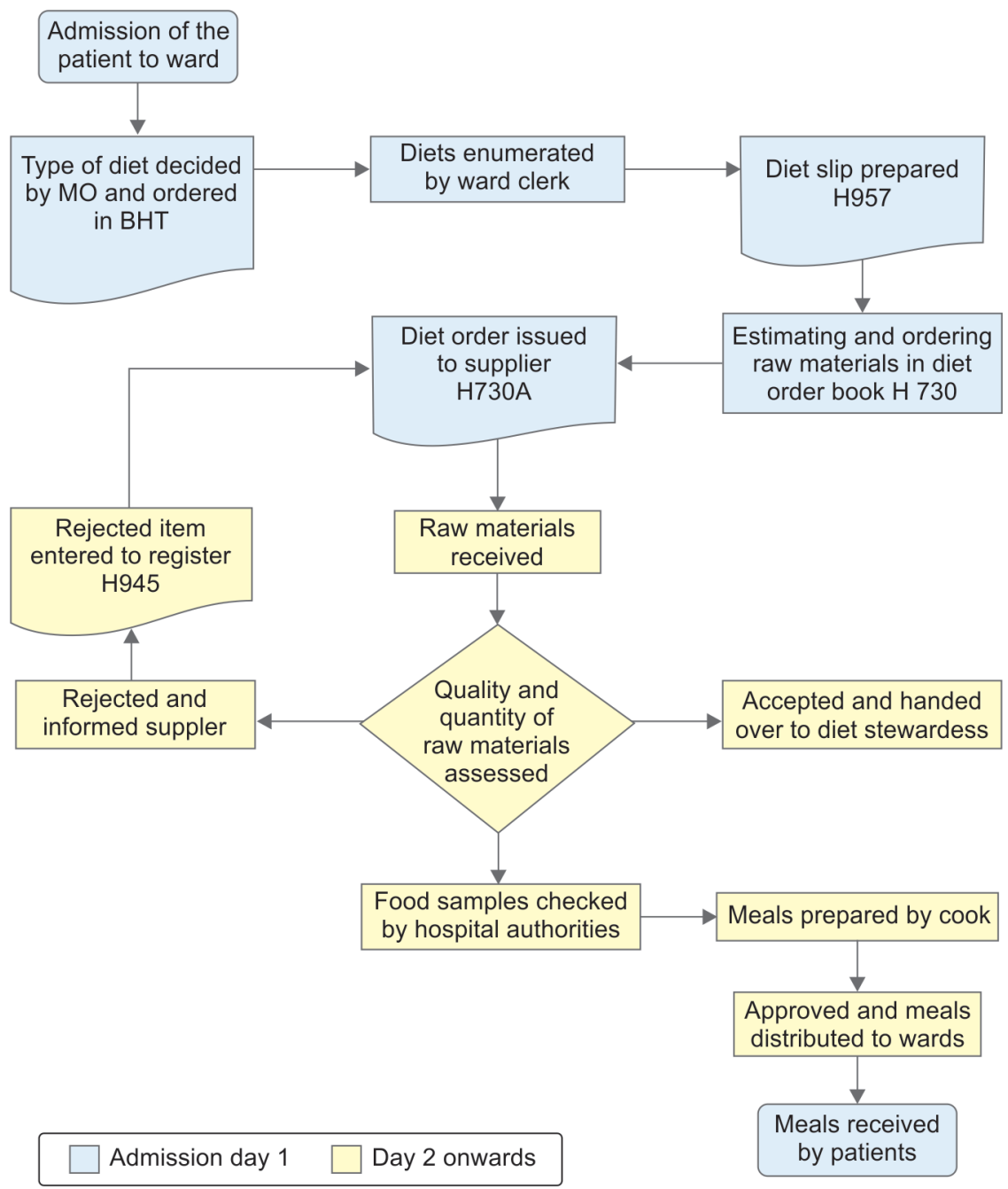

Based on the KIls and patients' survey, the following issues in the current process and practices of providing diet to inward patients in BHW were identified. The issues were classified into three groups:

- The diet menus

- The menus of the diet were solely prepared by the diet clerk with no inputs from MOs or NOs.

- The current menus were poor in variety and were not appealing.

- The menus were never known by patients till they receive food.

- Estimating diet requirement

- The diet clerk had to scan the whole BHT to estimate diet requirement for each patient and that was time-consuming and error-prone.

- Communication between the ward staff and the diet clerk was poor.

- Whether a patient expected a vegetarian or nonvegetarian diet was never asked.

- The diet requirement of a patient was calculated for the entire day without taking into consideration which meals he/she needed and which meals did not.
- Serving of diet

- The diet was not served at the bedside and the patient or the bystander had to walk to the health worker to obtain it.

- The tea and soup were served with the main meal to save time, which made the patients to refuse them.

- The dinner was served too early between 4:00 pm and 5:00 pm.

The patients' requests for hospital diet were assessed through the questionnaire. Only $11.64 \%$ (39/335) of total had expected all three meals from the hospital. It was observed that a majority of patients $(82.68 \% ; 277 / 335)$ required breakfast and dinner (Fig. 1).

Patients' choice to be inquired about whether they need diet, and how often they wanted the staff to do so was studied. Majority of patients $(97 \% ; 388 / 400)$ liked it to be asked whether they needed hospital food. Out of them, $90.75 \%$ (363/400) preferred to be asked daily about their diet requirements.

The patient choice of homemade meal over hospital diet was assessed. Among the total, 81.2\% (325/400) choose to have a combination of both (Fig. 2).

Wastage of food was evaluated by percentage of diets not consumed by the patients out of the ordered. It was studied in each 


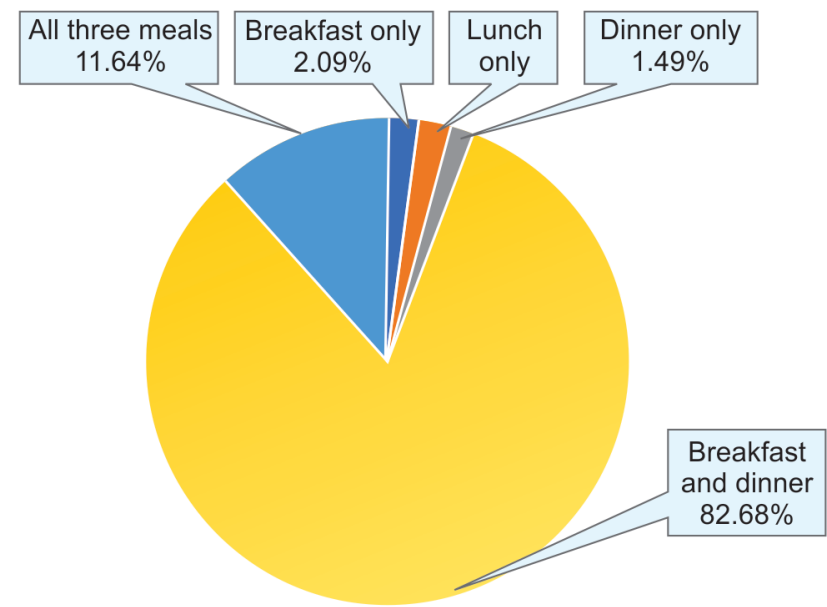

\section{Breakfast only Lunch only $\square$ Dinner only Breakfast and dinner $\square$ All three meals}

Fig. 1: Patients' request for hospital diet

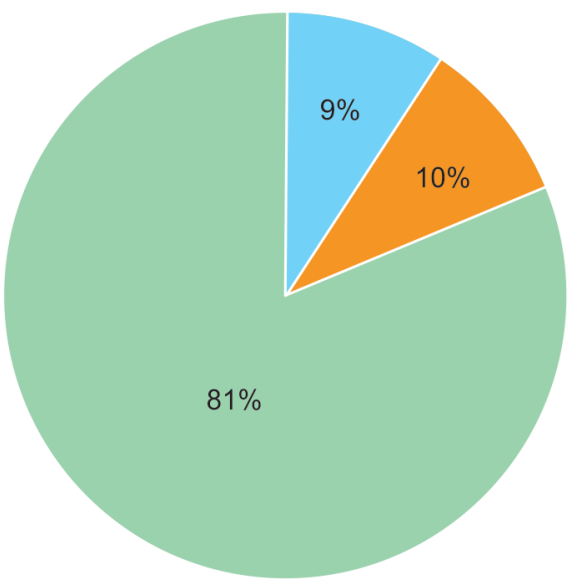

All meals from home

All meals from hospital

Meals from both places

Fig. 2: Patients' place of choice to obtain meals during hospitalization

Table 1: Patient satisfaction on selected attributes of provision of diet in Base Hospital Warakapola

\begin{tabular}{ll}
\hline Attribute & Percentage satisfied (\%) \\
\hline Timeliness of serving food & $223 / 400(56)$ \\
$\begin{array}{l}\text { Cleanliness in food handling while it } \\
\text { was served }\end{array}$ & $281 / 389(72.24)$ \\
$\begin{array}{l}\text { Hospitality of the staff when serving } \\
\text { diet }\end{array}$ & $299 / 393(76.08)$ \\
$\begin{array}{l}\text { General presentation/appearance } \\
\text { of food }\end{array}$ & $198 / 389(50.51)$ \\
$\begin{array}{l}\text { Taste of food } \\
\text { Aroma of food }\end{array}$ & $325 / 389(83.54)$ \\
Freshness of food & $335 / 389(88.62)$ \\
\hline
\end{tabular}

ward using the checklist in 1 month (May 2018). The total wastage of hospital food was $24.26 \%$ (649/2675).

Patient satisfaction on selected attributes of the provision of diet was given in Table 1.
The lowest satisfaction was observed regarding the timeliness of serving food (56\%), cleanliness in handling food when it was served $(72.24 \%)$, and general presentation/appearance of food served (50.51\%).

\section{Discussion}

Process mapping was the technique chosen in the current project to study the process of providing diet to the inward patients, which has been successfully applied in the past to introduce process reengineering to dietary services. ${ }^{18}$ The functional flow considered in this project extended from setting the menu to the serving of diet.

Assessing patients' satisfaction on hospital diet services was found to have a better response rate with inward patients rather than with discharged patients. ${ }^{19}$ This project used an interviewer-administered questionnaire for inward patients to assess their satisfaction.

Gaps were identified in setting the menu, estimating diet requirement, and serving of diet, which increased food wastage and lowered patients' satisfaction and ultimately reducing the efficiency of the diet service. 
The menu of the diet, which was prepared routinely by the diet clerk, had the primary focus on the quantity not the quality of food. The presentation of the portion did not have an appealing combination of color and texture.

As assessing the individual food intake of hospitalized patients ${ }^{20}$ to quantify food wastage was not feasible here with time and resource constraints, the project attempted to quantify the number of food portions not consumed by patients as an alternative measure.

It was a proxy indicator of the popularity of the menu as well. It was observed that food wastage was higher in medicine and surgery wards, which were relatively busy wards. Since the diet was estimated in the morning for the whole day, there is certain wastage of diets associated with day's discharges, which is proportionate to the patient turnover which explains the above observation.

Fragmentary nature of the hospital food service management and difficulties in communication between the kitchen and wards as was found in another project ${ }^{21}$ were an issue, brought about in the preinterventional interviews.

The poor communications between the ward staff and diet clerk are recognized as a major barrier to prevent food waste.

The practice of calculating the ${ }^{1}$ requirements of food for a patient was not on a mealwise basis, because when diets were ordered it was considered as for all three meals. But among the patients who expected hospital diet, majority $(88.36 \%)$ did not mean to have all three meals from the hospital, leading to overestimation and wasting of food.

The patients' choice of having a vegetarian diet was never considered before estimating the daily need of diets. So, the patients either refused the nonvegetarian items when it was served or those who were not expressive enough to do so discarded such components of the plate later.

The perceived hospitality of diet services in the hospital is associated with the manner food is served.

The serving schedule of extras including tea and soup was unsatisfactory according to the informants. The ward staff attempted to save time by serving the soup with the main meal. As per the government circular of the provision of diet in hospitals, the dinner was cooked sooner the raw materials were received by the same staff of the kitchen who covered the day duty shift, which caused the evening tea and the dinner to be served almost at the same time. This led to the tendency that tea was generally refused by the patients (KIIs). This project made the minor staff of the wards to collect the tea for patients first and serve it. The expected advantage of saving time by serving the dinner and tea together was outweighed by considering the convenience of patients and thereby reducing the waste of food.

The assessment of patients' satisfaction about hospital diet was based on patients' perceptions. As a result, comparison of some attributes such as satisfaction about taste and aroma of food among the two groups might have had limited objectivity.

Wastage of food was only assessed with the percentage of diets not consumed by patients. The wastage during preparation, storage, and distribution was disregarded due to constraints in time and resources. Therefore, the actual wastage would have been higher than what was estimated.

\section{Conclusion}

The process and practices of providing diet to inward patients in BHW were found to have gaps, which reduced patients' satisfaction and increased wastage of hospital food. The gaps were observed in setting of menu, estimating diet requirements, and serving of food.

These gaps were overcome by improving the setting of menu, displaying planned menu for patients in all wards, introducing a form to obtain diet requirements accurately, and improving the serving of food.

The level of satisfaction of both the patients and staff has significantly improved after the intervention regarding the processes and practices of providing diet and the wastage of food was also significantly reduced.

The outcome evaluation shows that the interventions implemented had been successful in improving the process and practices of providing diet to inward patients in BHW.

\section{References}

1. Ministry of Health, Sri Lanka. Manual of management of Teaching, Provincial, Base and Special Hospitals [Internet]. 1995. Available from: http://www.health.gov.lk/moh_final/english/public/elfinder/files/ publications/2017/ManualTHPHBHmanage.pdf.

2. Kamra V, Singh H, Kumar De K. Factors affecting patient satisfaction: an exploratory study for quality management in the health-care sector. Total Qual Manag Bus Excell 2016;27(9-10):1013-1027. DOI: 10.1080/14783363.2015.1057488.

3. Mishra PH, Mishra T. Study of patient satisfaction at a super specialty tertiary care hospital. Indian J Clin Pract [Internet] 2014. Available from http://medind.nic.in/iaa/t14/i12/iaat14i12p624.pdf.

4. Hwang L-JJ, Eves A, Desombre T. Gap analysis of patient meal service perceptions. Int J Health Care Qual Assur Inc Leadersh Health Serv 2003;16(2-3):143-153. DOI: 10.1108/09526860310470874.

5. Beck AM, Balknäs UN, Camilo ME, et al. Practices in relation to nutritional care and support-report from the Council of Europe. Clin Nutr Edinb Scotl 2002;21(4):351-354. DOI: 10.1054/cInu.2002.0555.

6. Hartley BA, Hamid F. Investigation into the suitability and accessibility of catering practices to inpatients from minority ethnic groups in brent. J Hum Nutr Diet Off J Br Diet Assoc 2002;15(3):203-209. DOI: 10.1046/j.1365-277x.2002.00364.x.

7. Dupertuis $Y$. Food intake in 1707 hospitalised patients: a prospective comprehensive hospital survey. Clin Nutr 2003;22(2):115-123. DOI: 10.1054/clnu.2002.0623.

8. Kondrup J, Johansen N, Plum LM, et al. Incidence of nutritional risk and causes of inadequate nutritional care in hospitals. Clin Nutr Edinb Scotl 2002;21(6):461-468. DOI: 10.1054/clnu.2002.0585.

9. Robinson M. The human right to food and nutrition. SCN News 1999(18):17-18.

10. McWhirter JP, Pennington CR. Incidence and recognition of malnutrition in hospital. BMJ 1994;308(6934):945-948. DOI: 10.1136/ bmj.308.6934.945.

11. Agarwal $E$, Ferguson $M$, Banks $M$, et al. Malnutrition and poor food intake are associated with prolonged hospital stay, frequent readmissions, and greater in-hospital mortality: results from the nutrition care day survey 2010. Clin Nutr 2013;32(5):737-745. DOI: 10.1016/j.clnu.2012.11.021.

12. Barton $A D$, Beigg $C L$, Macdonald IA, et al. High food wastage and low nutritional intakes in hospital patients. Clin Nutr 2000;19(6):445-449. DOI: 10.1054/clnu.2000.0150.

13. Edwards J, Nash A. Catering services. measuring the wasteline. Health Serv J 1997;107(5579):26-27.

14. Tucker HN, Miguel SG. Cost containment through nutrition intervention. Nutr Rev 1996;54(4 Pt 1):111-121. DOI: 10.1111/j.17534887.1996.tb03885.x.

15. Allison S. Institutional feeding of the elderly. Curr Opin Clin Nutr Metab Care 2002;5(1):31-34. DOI: 10.1097/00075197-20020100000006.

16. Löwik MR, van den Berg H, Schrijver J, et al. Marginal nutritional status among institutionalized elderly women as compared to those 
living more independently (dutch nutrition surveillance system). J Am Coll Nutr 1992;11(6):673-681. DOI: 10.1080/07315724.1992. 10718266.

17. Silverman MR, Gregoire MB, Lafferty LJ, et al. Current and future practices in hospital foodservice. J Am Diet Assoc 2000;100(1):76-80. DOI: 10.1016/S0002-8223(00)00023-7.

18. Sharma S, Mehrotra S. Application of principles of process re engineering for improvement of functional flows of dietary services of a tertiary care hospital. Int J Sci Res Publ [Internet] 2015;5(5):Available from: http://www.ijsrp.org/research-paper-0515/ ijsrp-p4136.pdf.
19. Watters CA, Sorensen J, Fiala A, et al. Exploring patient satisfaction with foodservice through focus groups and meal rounds. J Am Diet Assoc 2003;103(10):1347-1349. DOI: 10.1016/s0002-8223(03)01077-0.

20. Shahar S, Budiningsari D, Abd Manaf $Z$, et al. A simple dietary assessment tool to monitor food intake of hospitalized adult patients. J Multidiscip Healthc 2016;9:311-322. DOI: 10.2147/JMDH.S105000.

21. Hartwell HJ, Edwards JSA, Symonds C. Food service in hospital: development of a theoretical model for patient experience and satisfaction using one hospital in the UK NHS as a case study. [Internet] 2006. 226-238. Available from: http://eprints. bournemouth.ac.uk/12175/1/Food_Service.pdf. 